\title{
Development and validation of analytical methodology for quality evaluation of Tibolone in capsule pharmaceutical form through UV spectrophotometry
}

\author{
Augusto Cesar Corte*a, Leticia Lenz Sfair ${ }^{\mathrm{a}}$ \\ Universidade do Vale do Rio dos Sinos, Avenida Unisinos, 950, CEP: 93022-750, São Leopoldo, RS - Brasil \\ *Corresponding author:augustoccorte@gmail.com \\ Tibolone is a drug used as a hormonal repository and is very important due to its characteristic of helping to reduce the symptoms \\ triggered by the hormonal alteration during the climacteric period. Although widely used, the Brazilian Pharmacopoeia does not \\ have any information about this hormone. In the literature, only studies with methodologies using high performance liquid \\ chromatography for drug quantification were found. Thus, this study aimed to develop and validate analytical method using UV \\ spectrophotometry for quality control of Tibolone in capsule pharmaceutical form. The present study followed the validation \\ parameters present in RDC 166/2017 and ICH Q2 (R1), with acetonitrile as solvent and $225 \mathrm{~nm}$ as wavelength. Linearity showed \\ a correlation coefficient higher than 0.99 , precision presented a mean of $97.81 \%$ and accuracy reached a recovery percentage \\ average of $97.18 \%$. It was concluded that the method can be used in the quality control of Tibolone capsules, besides having a low \\ cost and a less complex methodology and easier to perform compared to HPLC.
}

Keywords: Tibolone, Quality Control, UV spectrophotometry, development and validation.

\section{Introduction}

Tibolone is known to be a hormonal repository that has great influence in the prevention of bone loss that usually happens during the climacteric and in the treatment of the symptoms caused by the hormonal alteration. It has estrogenic, androgenic and progestogenic activity. Through the progestogenic activity, the drug provides a protective effect on the endometrium and breasts (1).

The increase in the woman's life expectancy has had a great impact on the health of the female population and in many cases it is essential to adopt measures aimed at a better quality of life during and after the climacteric (2).

Discussions about hormone replacement therapy began around the 1960s, where, for all women who were going through the menopause period, estrogen therapy was prescribed, which itself caused several complications due to the increased endometrial level. In the 1980s, the protective characteristic caused by substances that mimicked the protective effect of progesterone was discovered, and in 1990 the first studies were carried out showing that hormone replacement therapy could aid in the reduction or disappearance of hormonal alterati on symptoms. However, it was only in 2002 that the prescription of hormone replacement therapies was initiated, only when the really needed intervention of medication was verified and not only for the reduction of the symptoms. (3).

After oral administration, the absorption of Tibolone is effected rapidly, due to its being widely absorbed, besides having rapid metabolization. Its maximum concentration in the organism is obtained between 1 - 4 hours after the administration. Part of the excretion occurs through the urine, but most of it is eliminated by the feces. (4).

The various changes that have been occurring commonly in the pharmaceutical industry have strengthened the need for innovation and quality assurance, mainly due to the great competitiveness in the sector. In this sense, quality control is no longer seen as a bureaucratic collection, becoming one of the most important processes of obtaining a pharmaceutical form, seeking to guarantee quality, effectiveness, safety and in response to consumer confidence. (5).

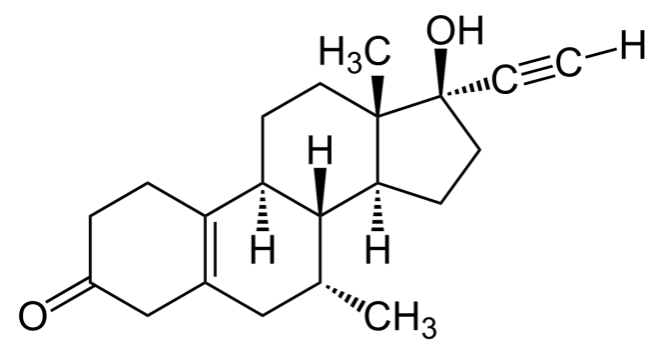

Figure 1. Chemical structure of Tibolone.

The need to perform a quality control that ensures greater efficiency, effectiveness and safety is related to the uniformity of procedures, processes, equipment, materials, activities or systems, making the development of efficient and fast analytical methodologies a practice of extreme value, providing greater security for users and analysts. (6). Since 2000, the increase in the number of drugs handled in Brazil, mainly due to the need for specific formulation and the lower cost, has led to a greater concern of the Agência Nacional de Vigilância Sanitária (ANVISA) regarding the quality of the products that are being produced and marketed by manipulation pharmacies. The first step was given through the publication of RDC No. 33 on 19 April 2000, which specified instructions on good handling practices in pharmacies. (7).

Currently, RDC No. 67, dated October 8, 2007, is in force, which aims to ensure the safety and quality of formulations produced in handling pharmacies throughout Brazil, in addition to establishing quality control criteria for facilities, equipment, human resources and procedures. (8).

Spectrophotometry is related to the electromagnetic absorption of molecules, and to the concentration and structure of molecules.

UV spectrophotometric methods are widely used in the development and validation of analytical methods for drug analysis. It is important to choose a solvent that does not interfere with the analysis wavelength (9).

Based on this knowledge, the present study aimed to develop and validate a simple, fast and low-cost analytical methodology for the quality control of Tibolone in capsule 
pharmaceutical form, based on UV spectrophotometry, since in the literature they are exclusively chromatographic methods.

\section{Experimental}

\section{Materials}

The Tibolone raw material (Lot: TBL / 217008), with declared content of $100 \%$, used as reference standard and $2.5 \mathrm{mg}$ capsules were purchased in a pharmacy of manipulation, located in São Leopoldo, Rio Grande do Sul. The excipients used in the preparation of the capsules were corn starch and silicon dioxide. The solvents used for the development of the method were: acetonitrile (Synth, Vetec, Chemical Group), ethanol (Vetec) and methanol (Synth) PA grade.

\section{Equipment}

The equipment used were UV-vis spectrophotometer model UV-1600 (Pro-tools) and spectrophotometer model UV2600 (Shimadzu). The glassware used during the experiments were made available by the Universidade do Vale do Rio dos Sinos and the tests carried out in the chemistry laboratories of the University and the Nutrifor Technological Institute.

\section{Development of the Methodology}

Based on the Tibolone monograph available in the British Pharmacopoeia (10), the acetonitrile, ethanol and methanol solvents were initially selected for solubilizing the drug.

To carry out the initial tests, the published study regarding the development and validation of high-performance liquid chromatography (HPLC) methods for Tibolone were used.

In the chromatographic analyzes the wavelength was 204 $\mathrm{nm}$ and $205 \mathrm{~nm}$ and the solvents employed as mobile phase were acetonitrile and water $(65: 35 \mathrm{v} / \mathrm{v}),(60: 40 \mathrm{v} / \mathrm{v})$, and acetonitrile, water and methanol $(60: 30: 10 \mathrm{v} / \mathrm{v}) .(11,12,13)$. A secondary standard was then prepared to test different concentrations to determine the one to present the most satisfactory results. The sample preparation was perfomed through a pool of 20 capsules. After preliminary tests, a spectrophotometer scan was performed between the wavelengths of 200 and $400 \mathrm{~nm}$ using solutions of each of the solvents mentioned above with reference standard, excipients and $200 \mu \mathrm{g} / \mathrm{mL}$ sample to verify the maximum absorption of the drug and possible interferences caused by the excipients. After defining the most suitable solvent to perform the method, it was to determine the most appropriate sample concentration.

\section{Validation}

To perform the validation of the analytical method, the guidelines presented in RDC 166/2017 of ANVISA (14) and the International Conference on Harmonization (15) were followed. The parameters evaluated were: specificity, linearity, precision, accuracy and robustness.

\section{Specificity}

The sample solutions, the reference standard and the simulated mixture of the excipients were scanned at the same concentration in the 200 to $400 \mathrm{~nm}$ range in order to evaluate their interference in the quantification of the drug. An amount of powder equivalent to $10 \mathrm{mg}$ of Tibolone was used to prepare the excipient and sample solution, whereas $10 \mathrm{mg}$ of the reference standard was used for the raw material solution.

\section{Linearity}

Linearity was evaluated through the construction of three analytical curves ranging from 60 to $140 \%$ of the work concentration. For this purpose, a stock solution of secondary standard $(1.0 \mathrm{mg} / \mathrm{mL})$ was prepared from which aliquots were drawn and diluted in $10 \mathrm{~mL}$ volumetric flasks with acetonitrile, resulting in concentrations of 120, 160, 200, 240 and $280 \mu \mathrm{g} / \mathrm{mL}$. It was decided to use $10 \mathrm{~mL}$ volumetric flasks in the dilutions to avoid waste and minimize the generation of waste due to the need to use organic solvent. Statistical analysis of the data was performed through ANOVA with a 95\% confidence interval.

\section{Precision}

Precision was expressed by repeatability, intermediate precision or reproducibility. Samples were prepared regardless. (16).

To evaluate the repeatability, six independent samples were prepared at a concentration of $200 \mu \mathrm{g} / \mathrm{mL}$ and the absorbance readings were performed in the spectrophotometer. In the intermediate precision the same procedure of preparation of six independent samples of the same concentration was carried out by a different analyst and on different days. The result was expressed by the relative standard deviation value ( $\mathrm{RSD} \%)$.

\section{Accuracy}

Accuracy was evaluated by the method of addition of standard in sample through 9 determinations, contemplating the linear interval of the analytical method. Three levels of addition $(25,50$ and $75 \%$ of the reference standard) in the sample were performed from the starting point of the curve of $120 \mu \mathrm{g} / \mathrm{mL}$, in triplicate.

For the calculation of the recovery percentage, the formula available in RDC 166 of 2017 was used (14).

Experimental mean concentration Recovery =

Standard added - Sample concentration X 100

Theoretical concentration added

\section{Robustness}

The verification of robustness was achieved by the realization of linearity with variation of the solvent brand and realization of the method in two different laboratories and with different equipments. 


\section{Results and discussion}

Based on the spectra obtained by ultraviolet region scanning, the wavelength of $225 \mathrm{~nm}$ was selected for validation of the analytical method, taking into account the maximum absorption of Tibolone and the non-interference of the excipients at this wavelength.

From the tests performed it was observed that it was possible to work by weighing the minimum amount of reference standard $(10 \mathrm{mg})$ using a small volume of organic solvent to prepare the sample.

Through the spectra obtained in the analysis of the solvents, it was verified that ethanol and methanol have absorption peaks in wavelength very similar to the one of the Tibolone, being able to cause interferences in the readings of absorbance of the drug, whereas the acetonitrile does not present peaks that can interfere in the analysis of the drug, basing its choice for development and validation of the method.

The specificity evaluation was performed by analyzing the spectra of the sample solutions, the reference standard and the simulated mixture of the excipients $(200 \mu \mathrm{g} / \mathrm{mL})$ in the range from 200 to $400 \mathrm{~nm}$, demonstrating that the excipients used in the capsule formulation did not interfere in the quantification of Tibolone in the wavelength of $225 \mathrm{~nm}$, as shown in Figure 2.

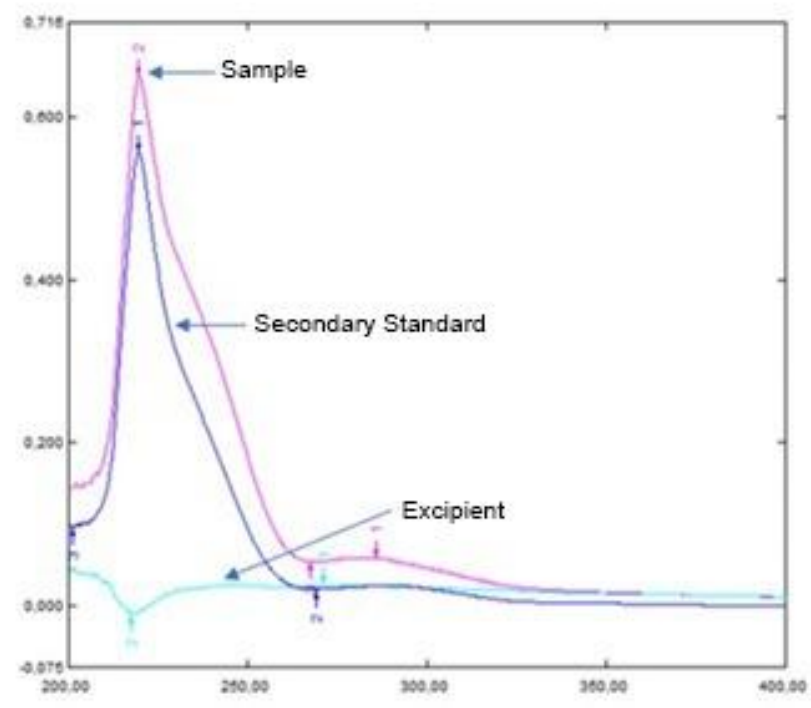

Figure 2: Absorbance of Tibolone sample, secondary standard and excipients $(200 \mu \mathrm{g} / \mathrm{mL})$ in acetonitrile.

The method was linear with $\mathrm{R}^{2}$ of 0.9992 and correlation coefficient ( $r$ ) of 0.9996 , and the recommended value is a correlation coefficient value higher than 0.99 . The equation of the line was $y=0.0021 x+0.0076$ (Figure 3) and in the statistical analysis by ANOVA an $\mathrm{F}$ value of 0.37 was found, which was lower than the tabulated value (4.53).

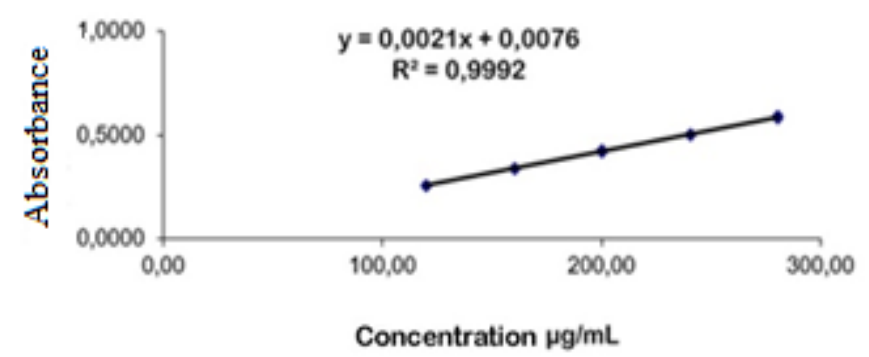

Figure 3: Linearity analytical curve.

The repeatability was evaluated by the preparation of six independent samples in the working concentration, while in the intermediate precision another analyst was responsible for the preparation of the six samples. From the results obtained, the values of RSD\% were calculated. The repeatability and intermediate precision presented RSD values of $2.32 \%$ (day 1), $2.65 \%$ (day 2) and $2.92 \%$ of RSD intraday (Table 1). The new resolution of ANVISA (14) does not specify a reference value, but the old resolution (17) recommended a RSD value less than 5\%.

Accuracy was assessed by adding standard in sample and determined by recovery percentage. According to Table 2, the results obtained were satisfactory, obtaining recovery percentages close to $100 \%$. The accuracy values are between 95 and $105 \%$, assigning an acceptable characteristic for this parameter.

The method remained robust even when the solvent brand variation was performed and also through the results obtained from the tests performed in two different laboratories and with different glassware and equipment, obtaining a difference between the results of less than $1 \%$. 
Table 1: Precision and intermediate precision results obtained by analysis UV spectrophotometric.

\begin{tabular}{cccccccc}
\hline Day & Sample & Sample & Sample & Sample & Sample & Sample & RSD \\
& $\mathbf{1}$ & $\mathbf{2}$ & $\mathbf{3}$ & $\mathbf{4}$ & $\mathbf{5}$ & $\mathbf{6}$ & \\
& & & & & & & \\
& & & & & & & \\
\hline $\mathbf{1}$ & $95.55 \%$ & $97.00 \%$ & $99.10 \%$ & $93.03 \%$ & $94.69 \%$ & & \\
\hline $\mathbf{2}$ & $101.19 \%$ & $102.23 \%$ & $97.30 \%$ & $100.53 \%$ & $95.22 \%$ & $99.91 \%$ & $\mathbf{2 . 6 5 \%}$ \\
\hline RSD Intraday & & & & & & & \\
\hline
\end{tabular}

RSD: Relative Standard Deviation.

Table 2: Percentage values of Tibolone recovery by adding pattern to sample by UV spectrophotometry method.

\begin{tabular}{cccccc}
\hline & & Tibolone $(\boldsymbol{\mu g} / \mathbf{m L})$ & Average & Content $(\%)$ \\
\hline $\mathbf{2 5 \%}$ & 34.66 & 27.44 & 28.44 & 30.18 & 100.6 \\
\hline $\mathbf{5 0 \%}$ & 58.22 & 56.44 & 57.77 & 57.47 & 95.78 \\
\hline $\mathbf{7 5 \%}$ & 86.55 & 84.68 & 85.72 & 85.65 & 95.16 \\
\hline
\end{tabular}

Content: Recovery percentage.

\section{Conclusion}

Through the analysis of the results, it was possible to verify that the developed method meets the parameters required for validation, obtaining proof of specificity, linearity, precision, accuracy and robustness. Since it is proven that the methodology is satisfactory, it is indicated the use of the same to perform quality control of Tibolone in several areas, but mainly in handling pharmacies and laboratories that do not have sophisticated equipment like a liquid chromatograph and need simpler methodologies as well enabling lower cost and faster analysis, however that are effective and accurately portray the results obtained.

\section{Conflict of interest}

The authors declare no conflicts of interest.

\section{References}

1. Pantaleão JAS, Henriques HN, Carvalho ACB, Pollastri CE, Filho Soares PJ, \& Guzmán-Silva MA. Efeito da tibolona sobre o endométrio de ratas castradas. Revista Brasileira de Ginecologia e Obstetrícia, 31(3): 124-130, 2009.

2. Brazil. Ministério da Saúde. Secretaria de Atenção à Saúde. Política Nacional de Atenção à Saúde da Mulher: princípios e diretrizes. Brasília, 2004. 44p.

3. Pardini D. Terapia de reposição hormonal na menopausa. Arquivos Brasileiros de Endocrinologia \& Metabologia, 58(2): 172-181, 2014.
4. Tibial: tibolona. Farmacêutico responsável: Dr. Marco Aurélio Limirio G. Filho. Goiás: Brainfarma Indústria Química e Farmacêutica S.A. 2016. Bula de medicamento.

5. Kesic, D. Strategic analysis of the world pharmaceutical industry. Journal of Contemporary Management Issues. 14(1): 59-76, 2009.

6. Ribani M. Validação em métodos cromatográficos e eletroforéticos. Quim Nova. 2004; 27:771-780.

7. Bonfilio R, Emerick GL, Netto Júnior A \& Salgado HRN. Farmácia Magistral: sua importância e seu perfil de qualidade. Revista Baiana de Saúde Pública. 34(3): 653-664, 2010.

8. Brazil. Agência Nacional de Vigilância Sanitária. 2007 Resolução da Diretoria Colegiada RDC no 67 de 8 de outubro de 2007. Dispõe sobre Boas Práticas de Manipulação de Preparações Magistrais e Oficinais para Uso Humano em farmácias. Diário Oficial da União: Brasília.

9. Brazilian Pharmacopoeia, 5th Ed., v1, Agência Nacional de Vigilância Sanitária, Brasília, 2010.

10. British Pharmacopoeia. The Stationary Office: Pharmacopoeia Comission British, 2011, p.3300.

11. Ângelo, ML. Análise farmacêutica de tibolona em cápsulas magistrais por cromatografia líquida de alta eficiência. 2013. Alfenas. 106 p. Monografia (Mestrado), Universidade Federal de Alfenas.

12. Rosa HB, Tolotti RC, Miron DS, \& Souza KCB. Desenvolvimento e validação de método para o 
doseamento de tibolona em cápsulas por cromatografia líquida de alta eficiência. Química Nova, 35(5): 10301035, 2012.

13. Jadhav V, Gholve S \& Kadam V. Validation of highperformance liquid chromatographic method for the determination of Tibolone in bulk and pharmaceutical dosage form. Journal of Pharmacy Research, 2(4): 694697, 2009.

14. Brazil. Agência Nacional de Vigilância Sanitária. 2017. Resolução RDC n ${ }^{\circ} 166$ de 27 de julho de 2017. Dispõe sobre a validação de métodos analíticos e dá outras providências, Diário Oficial da União: Brasília.
15. International Conference on Harmonization (ICH), Validation of Analytical Procedures: Text and Methodology, Q2 (R1), 2005.

16. Brazilian Pharmacopoeia, 5th Ed., v2, Agência Nacional de Vigilância Sanitária, Brasília, 2010.

17. Brazil. Agência Nacional de Vigilância Sanitária. 2003 Resolução da Diretoria Colegiada (RE) n ${ }^{\circ} 899$ de 29 de maio de 2003. Guia para validação de métodos analíticos e bioanalíticos métodos analíticos. Diário Oficial da União: Brasília. 